\section{PENELITIAN PENERAPAN SOL KARET SEPATU \\ KANVAS UNTUK OLAH RAGA PADA INDUSTRI DITINJAU DARI SIFAT KETAHANAN KIKIS DAN KEKERASANNYA}

Oleh : Any Setyaningsih, Arum Yuniari, Sri Brataningsih Puji Lestari

\section{ABSTRACK}

Appied research rubber sole for canvas shoes sport of industry have observed of properties abrassion resistance and hardness with perform research on the process to shape sole in industry with variation resistance and hardness with perform rese $145,150,155 \mathrm{~kg} / \mathrm{cm} 2$ on temperature $150^{\prime} \mathrm{C}$ on the result time of $4,5,6,7,8 \mathrm{~min}$. 15 variation soles, until of result properties abrassion resistance $=0.1410 \mathrm{~mm} 3 / \mathrm{kgm}$ and hardness means SNI 0171-1987A: Canvas Shoes with Rubber Sole for Sport.

\section{INTISARI}

Penelitian penerapan sol karet sepatu kanvas untuk olah raga pada industri ditinjau dari sifat ketahanan kikis dan kekerasan dilakukan penelitian dengan proses pencetakan sol di industri dengan variasi kikis dan kekerasan dilakukan penelitian dengan proses pencetakan sol di inda suhu $150^{\circ} \mathrm{C}$ diperoleh waktu pencetakan sol $4,5,6,7,8$ menil dasil penelitian diperoleh sifat ketahanan kikis $=0,1410 \mathrm{~mm} / \mathrm{kgm}$ 15 variasi sol cetak, sehingga dari hasil penelitan diperoleh sif k ka waktu 6 menit dan suhu $150 \mathrm{C}$ dan kekerasan $=70$ shore A dicetak dengan variasi tekanan $150 \mathrm{~kg} / \mathrm{cm}$, waktu 6 ment dan suhu 150 .
memenuhi persyaratan SNI 0171-1987 A : Sepatu Kanvas dengan Sol Karet untuk Olah Raga.

\section{PENDAHULUAN}

Bagian yang terpenting dari sepatu khususnya sepatu untuk olah raga adalah sol, karena sol akan menerima beban yang berat dan gesekan yang berulang-ulang pada waktu dikenakan untuk berolah raga. Oleh karena itu sol sepatu untuk olah raga haruslah mempunyai persyaratan yang dapat menunjang fungsi dan penggunaannya terutama sifat ketahanan kikis dan kekerasannya.

Ketahanan kikis dan kekerasan sepatu olah raga merupakan faktor yang penting sebab kalau sol sepatu olah raga mudah terkikis dan lunak dapat mengakibatkan kembangan sol menjadi rata dan sepatu menjadi licin sehingga mudah tergelincir dan membahayakan kalau dipakai.

Elastomer (karet alam) merupakan bahan baku pembuatan sol karet. Untuk pembuatan sol karet disamping elastomer diperlukan bahan tambahan serta bahanbahan kimia yang lain. Jumlah bahan tambahan serta bahan-bahan kimia harus ditambahkan pada elastomer tergantung dari jumlah elastomer yang digunakan. Pada prinsipnya elastomer alam menentukan sifat dasar barang-barang karet yang dihasilkan. Disamping elastomer alam, macam dan jumlah bahan pengisi juga sangat liefyentinih terhadap sifat barang jadinya. Atau dengan kata lain bahan-bahan kimia fini hatian pengisi terpengaruh oleh sifat proses serta campuran kompon karet (3).

fifat barang jadi juga dipengaruhi proses vulkanisasi. Vulkanisasi adalah pinitiahan dari molekul karet karena terbentuknya crosslink. Zat pemvulkanisas ying diperlukan agar terbentuk crosslink adalah sulphur atau peroksida yang lain, Hiilanis kadang dapat pula dipakai energi dengan radiasi tinggi. Dengan adanya Hrinilink maka akan terjadi perubahan sifat karet dari keadaan thermoplastis menjadi Hinifi Ierbentuknya crosslink tergantung dari beberapa hal antara lain zat petivulk anisasi, aktivitas dan waktu reaksi.

CHebetapa Lahapan proses vulkanisasi :

Hia vilkanisasi yaitu pada saat vulkanisasi dimulai.

Vulk anisasi optimum.

Giver vulkanisasi (diluar curve) kembali ke sifat semula (3).

Aila beberapa cara untuk mengerjakan vulkanisasi, pemilihan penggunaan Hinf walah satu cara tergantung dari jenis barang akhir yang dikehendaki, ukuran thita model dari produk akhir, selain itu juga mempertimbangkan harga produknya. C Cakan prakctek vulkanisasi yang sangat penting adalah efisiensi transfer panas. Dalam Himei cetak vulkanisasi yang sangat penting adalah kompon karet yang sesuai Hilekakian dalam cetakan logam, kemudian dipanaskan diantara dua plat yang femaidian dipress. Plat dari mesin press tersebut biasanya dipanaskan dengan uap, fempefatie yang digunakan berkisar $140 \mathrm{C}$, kadang-kadang juga menggunakan ieniperafur tinggi yaitu mencapai 170 C. Selain itu pemanasan plat dapat juga dilakukin dengan menggunakan gas atau listrik. Plat bagian atas biasanya tetap, inilain plat bagian bawah dapat bergerak keatas dan kebawah yang digerakkan wieli alat penekan hydraulik. Tekanan hydraulik dikembangkan langsung dari suatu

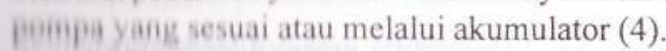

llerdasarkan penelitian pembuatan kompon sol karet sepatu kanvas untuk Ghih raga mudah dicapai persyaratan sesuai dengan SNI 0171-1987A : Sepatu Kanvas Itinisan fol Karet untuk Olah Raga. Namun demikian belumlah cukup karena hasil Heneliilan tersebut masih merupakan kompon, belum sampai barang jadinya. Untuk Hiengetahui sejauh mana penelitian ini maka perlu diadakan penelitian penerapan Hit harei sepatu kanvas untuk olah raga pada industri.

\section{MAIEMIBAN METODE}

Minieit

Materi penelitian meliputi bahan baku, bahan pembantu yang tercantum inalan formulasi sebagai berikut :

1 Hale crepe

100 bagian

Yai XII No. 25 Th. 1997/1998 
2. Asam stearat

3. $\mathrm{ZnO}$

4. $\mathrm{MgSiO} 2 / \mathrm{A} 1 \mathrm{SiO}_{2}$

5. Naphthenic oil

6. Paraffin Wax

7. $\mathrm{PBN}$

8. MBTS

9. $\mathrm{DEG}$

10. $\mathrm{TiO} 2$

11. TMT

12. Sulphur
0,5 bagian

5 bagian

25/25 bagian

9 bagian

0,5 bagian

1 bagian

bagian

bagian

bagian

bagian

bagian

\section{Peralatan}

Peralatan pembuatan sol karet olah raga di industri meliputi :

a. Alat untuk pembuatan kompon

- timbangan

- two roll mill

- pisau kompon

- scop

- bak tempat aging kompon (ukuran $1 \times 4 \mathrm{M}$ )

- kuda-kuda tempat gantungan kompon

b. Alat untuk pencetakan sol

- mesin kempa vulkanisasi bersusun 4 (hydraulic press) dilengkapi dengan alat pemanas thermopac dan hydraulic pump untuk tekanan plat pencetak.

- cetakan sol

- gunting

- kaos tangan

Metode berikut :

Penelitian dilaksanakan di industri dengan melalui tahapan penelitian sebagai

\section{Komponding}

- bahan baku dan bahan pembantu ditimbang sesuai formulasi penelitian

Hahisil yain sudah ditimbang dicampur dengan alat two roll mill besar (i)ibapanilas $50 \mathrm{~kg}$ ).

finia mola kuet alam (pale crepe) digiling sampai plastis, kemudian ditambahkan Giiraflin Wak, $/ \mathrm{nO}$ dan asam stearat.

Liminilan difambahikan naphthenic oil, ultrasil, alumunium silikat dan DEG giling

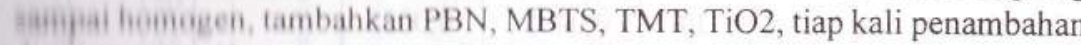
ilisilitis sampai homogen

I fiminifian kompon dipotong-potong sampai 8 lembar dan didiamkan sampai thaili inalam

\section{Penetakan}

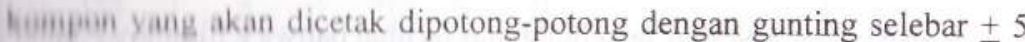
(iil. banjang $\pm 50 \mathrm{~cm}$.

Heati Kempa vulkanisasi (hydraulic press) dipanaskan pada suhu $150 \mathrm{C}$.

Gitelahi alat cetakan disiapkan, potongan kompon diletakkan diatas cetakan dini dipotong-potong sesuai dengan kebutuhan cetakan.

Lemidian pengatur waktu distel sesuai dengan kebutuhan yaitu (4, 5, 6, 7 (lan 11$)$ menif dan besarnya tekanan diatur dengan cara memutar pressure Hiwiti hi pada hydraulic pump yaitu $(145,150,155) \mathrm{kg} / \mathrm{cm}$, sehingga diperoleh If variasipencetakan.

tetah an yang sudah berisi kompon dimasukkan kedalam dua plat pencetak. Keinuidian mulai dipress dengan cara menekan knop press.

weie lah waktu press sesuai dengan pengatur waktu yang dikehendaki, secara hitimatis press membuka sendiri.

kemudian cetakan dikeluarkan dari hyraulic press setelah sol karet dingin dan an karet dikeluarkan dari cetakan dilakukan trimming.

\section{Pemugian}

Hal hasil penelitian ini diuji sifat ketahanan kikis dan kekerasannya.

\section{WAGII MINITIAN DAN PEMBAHASAN}

\section{IIABII BENITIAN}

Hasil penelitian tertera dalam lampiran 1. Kemudian dihitung secara statistik temian menggunakan metode faktorial. 
Tabel 1 : Analisa Sidik Ragam (ANOVA) untuk ketahanan Kikis

\begin{tabular}{|l|c|c|c|c|c|c|}
\hline Sumber Variasi & $\mathrm{dk}$ & $\mathrm{jk}$ & $\mathrm{R}$ & $\mathrm{F}$ hitung & \multicolumn{2}{|c|}{$\mathrm{F}$ tabel } \\
\cline { 6 - 7 } & & & & & $5 \%$ & $1 \%$ \\
\hline Ulangan & 2 & 0,0039 & 0,00195 & & & \\
Perlakuan & 14 & 0,0492 & 0,0035 & & & \\
Waktu & 4 & 0,0243 & 0,0061 & & & \\
Tekanan & 2 & 0,0078 & 0,0069 & 2,0 & 2,71 & 4,07 \\
Interaksi Waktu X Tekanan & 8 & 0,0171 & 0,0021 & 1,3 & 3,34 & 5,45 \\
Kekeliruan & 28 & 0,0844 & 0,0030 & 0,7 & 2,29 & 3,23 \\
\hline Total & 44 & 0,1375 & & & & \\
\hline
\end{tabular}

Dari tabel ANOVA tersebut diatas terlihat bahwa $\mathrm{F}$ hitung $<\mathrm{F}$ tabel $5 \%$ dan $1 \%$ berarti dari faktor waktu dan tekanan serta interaksinya tidak ada perbedaan nyata.

Tabel 2 : Analisa Sidik Ragam (ANOVA) untuk Kekerasan

\begin{tabular}{|l|c|c|c|c|c|c|}
\hline Sumber Variasi & $\mathrm{dk}$ & $\mathrm{jk}$ & $\mathrm{R}$ & $\mathrm{F}$ hitung & \multicolumn{2}{|c|}{$\mathrm{F}$ tabel } \\
\cline { 6 - 7 } & & & & & $5 \%$ & $1 \%$ \\
\hline Ulangan & 2 & 0,40 & 0,20 & & & \\
Perlakuan & 14 & 118,00 & - & & & \\
Waktu & 4 & 58,00 & 14,50 & $53,4266^{*}$ & 2,71 & 4,07 \\
Tekanan & 2 & 19,6 & 9,80 & $36,1090^{*}$ & 3,34 & 5,45 \\
Interaksi Waktu X Tekanan & 8 & 40,40 & 5,05 & $18,6072^{*}$ & 2,29 & 3,23 \\
Kekeliruan & 28 & 7,60 & 0,2714 & & & \\
\hline Total & 44 & 126,0 & & & & \\
\hline
\end{tabular}

* berbeda nyata

Dari tabel ANOVA tersebut diatas terlihat bahwa faktor waktu dan tekanan berpengaruh nyata juga interaksi waktu dan tekanan berpengaruh nyata karena $\mathrm{F}$ hitung lebih besar dari $\mathrm{F}$ tabel $5 \%$ dan $1 \%$.
Batani bunean's test

\begin{tabular}{|c|c|c|c|c|c|}
\hline His & Tekanan & Waktu & Total & Rata-rata & Notasi dengan Duncan's \\
\hline 1 & 145 & 8 & 204 & 68 & a \\
\hline 1 & 145 & 7 & 207 & 69 & $b$ \\
\hline 1 & 145 & 6 & 207 & 69 & $b$ \\
\hline 1 & 150 & 8 & 207 & 69 & b \\
\hline 4 & 155 & 8 & 210 & 70 & c \\
\hline 光 & 155 & 7 & 210 & 70 & c \\
\hline 1 & 155 & 4 & 210 & 70 & $\mathrm{c}$ \\
\hline ii & 145 & 5 & 210 & 70 & c \\
\hline$y$ & 155 & 6 & 210 & 70 & c \\
\hline i1) & 150 & 6 & 210 & 70 & c \\
\hline 11 & 155 & 5 & 213 & 71 & cd \\
\hline 11 & 150 & 7 & 213 & 71 & $\mathrm{~cd}$ \\
\hline 11 & 150 & 4 & 216 & 72 & $\mathrm{~d}$ \\
\hline 11 & 145 & 4 & 216 & 72 & d \\
\hline 11 & 150 & 5 & 225 & 75 & $\mathrm{e}$ \\
\hline
\end{tabular}

f fierasan lettinggi dicapai pada tekanan $150 \mathrm{~kg} / \mathrm{cm}$ dengan waktu 6 menit dengan (iiliai 70 blore A. Untuk kekerasan $>70$ shore A tidak memenuhi persyaratan SNI.

\section{ME MIIIIIASAN}

1. Cumk Ketahianan kikis faktor waktu, tekanan dan interaksi waktu dengan tekanan litak ada perbedaan sehingga semua formulasi tidak berbeda nyata dan keialianan Kikisnya memenuhi persyaratan SNI 0171 - 1987 A, yang terbaik ailalah ketahanan kikis dengan variasi tekanan $150 \mathrm{~kg} / \mathrm{cm}$ dan waktu 6 menit.

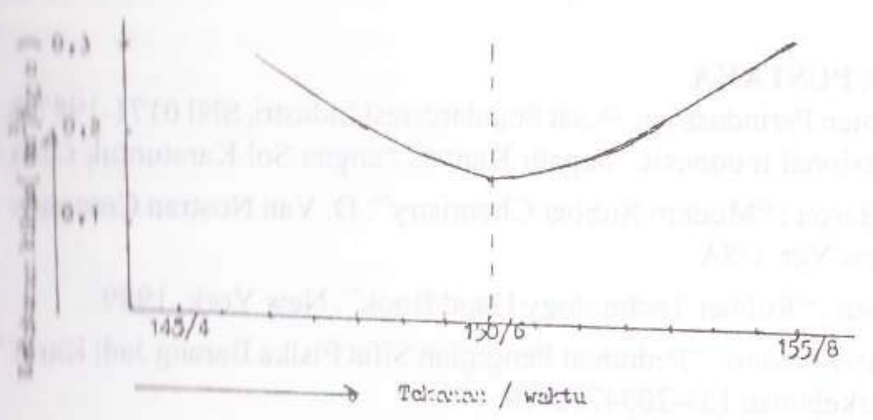

Gambar I Grafik hasil uji ketahanan kikis sol sepatu kanvas untuk olah raga. 
2. Ditinjau dari kekerasannya faktor waktu, tekanan dan interaksi waktu dengan tekanan ada perbedaan nyata.

Dilihat dari Notasi Duncan's test nilai kekerasan tertinggi pada variasi tekanan $150 \mathrm{~kg} / \mathrm{cm}$, waktu 6 menit.

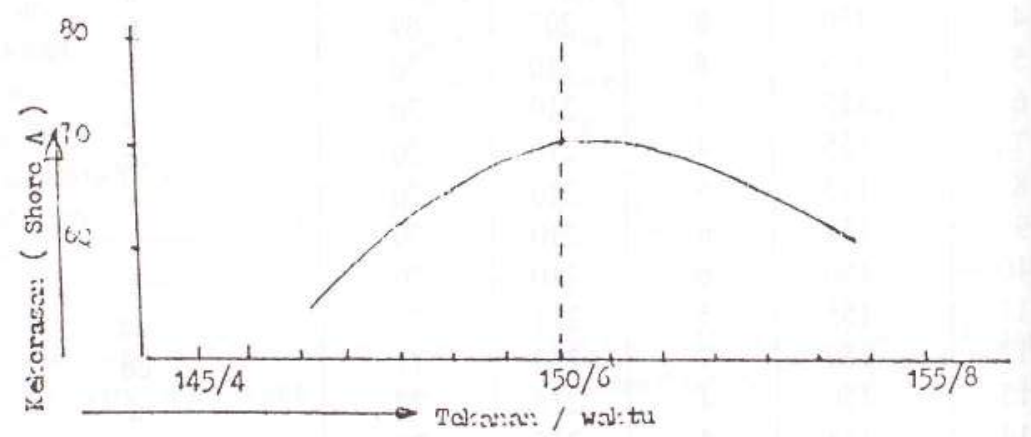

Gambar 2 : Grafik hasil uji kekerasan sol sepatu kanvas untuk olah raga.

\section{KESIMPULAN}

Formulasi dengan susunan : Pale crepe 100 bagian, asam stearat 0,5 bagian, $\mathrm{ZnO} 5$ bagian, MgSiO2 25/25 bagian, naphthenic oil 9 bagian, paraffin wax 0,5 bagian, PEN 1 bagian, MBTS 1 bagian, DEG 2 bagian, TiO2 5 bagian, TMT 1 bagian, sulphur 2 bagian diproses dan dicetak dengan variasi tekanan $150 \mathrm{~kg} / \mathrm{cm}$ dan waktu 6 menit ketahanan kikisnya mencapai $0,1410 \mathrm{~mm} / \mathrm{kgm}$ adalah yang terbaik dengan kekerasan mencapai 70 shore A dan memenuhi persyaratan SNI 0171 - 1987 A Sepatu Kanvas dengan Sol Karet untuk Olah Raga.

\section{DAFTAR PUSTAKA}

1. Deprtemen Perindustrian, Pusat Standardisasi Industri, SNI 0171-1987 A : Standa Nasional Indonesia "Sepatu Kanvas dengan Sol Karetuntuk Olah Raga".

2. Harry Baron : "Modern Rubber Chemistry". D. Van Nostran Company Inc 194 New Yor, USA.

3. Hofmann : "Rubber Technology Hand Book", New York, 1989.

4. Soewarti Soeseno : "Pedoman Pengujian Sifat Fisika Barang Jadi Karet", Menara Perkebunan 153-20547, 1979

5. Suntoyo Ir : "Experimental Design".

6. T. Kusnata : "Pengujian pada Karet", Balai Penelitian Perkebunan Bogor.

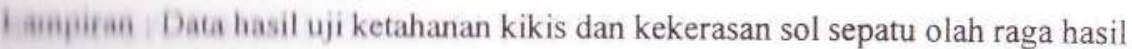
peierapan pada industri.

\begin{tabular}{|c|c|c|c|c|c|c|c|c|}
\hline \multirow{4}{*}{ 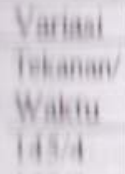 } & \multicolumn{8}{|c|}{ Pengujian/Satuan } \\
\hline & \multicolumn{4}{|c|}{ Ketahanan kikis $/ \mathrm{mm} 3 / \mathrm{kg}$} & \multicolumn{4}{|c|}{ Kekerasan(ShoreA) } \\
\hline & \multicolumn{3}{|c|}{ Ulangan } & \multirow{2}{*}{$\begin{array}{c}\text { Rata-rata } \\
0,1129\end{array}$} & \multicolumn{2}{|c|}{ Ulangan } & \multicolumn{2}{|c|}{ Rata-rata } \\
\hline & 0,1422 & 0,0943 & 0,1007 & & 72 & 72 & 72 & 72 \\
\hline $141 / 1$ & 0,1403 & 0,1529 & 0,1160 & 0,1364 & 70 & 70 & 70 & 70 \\
\hline $1414 / 6$ & 0.1156 & 0,1514 & 0,2169 & 0,1611 & 70 & 69 & 68 & 69 \\
\hline $119 / 1$ & 0,1671 & 0,1710 & 0,1524 & 0,1635 & 69 & 70 & 68 & 69 \\
\hline $111 / 11$ & $0,15,45$ & 0,2506 & 0,1979 & 0,2010 & 68 & 68 & 68 & 68 \\
\hline $130 / 4$ & 0,0777 & 0,1435 & 0,1143 & 0,1118 & 72 & 72 & 72 & 72 \\
\hline $130 / 4$ & 0,1274 & 0,1187 & 0,4132 & 0,2197 & 75 & 75 & 75 & 75 \\
\hline 1806 & 0,1141 & 0,1194 & 0,1695 & 0,1410 & 70 & 70 & 70 & 70 \\
\hline $180 / 1$ & 0,1558 & 0,1234 & 0,1352 & 0,1381 & 70 & 70 & 70 & 70 \\
\hline $190 / 11$ & 0,2015 & 0.1795 & 0,1675 & 0,1828 & 68 & 70 & 69 & 69 \\
\hline $11 \mathrm{~A} / \mathrm{A}$ & 0,0812 & 0,1692 & 0,1952 & 0,1485 & 70 & 70 & 70 & 70 \\
\hline $1,44 / 5$ & 0,1952 & 0,1505 & 0,1768 & 0,1741 & 72 & 70 & 71 & 71 \\
\hline $115 / 6$ & 0,1971 & 0,2327 & 0,1513 & 0,1937 & 70 & 70 & 70 & 70 \\
\hline 1487 & 0,2026 & 0,2167 & 0,1957 & 0,2050 & 70 & 70 & 70 & 70 \\
\hline $134 / 1$ & 0.2477 & 0,1803 & 0,1747 & 0,2009 & 70 & 70 & 70 & 70 \\
\hline $\begin{array}{l}\text { 4Niा } \\
01 / 1010\end{array}$ & & maks. I & & & & $0-7$ & & \\
\hline
\end{tabular}

